\title{
Losses influence of a Fabry Perot resonator on the effect of the optical multistability in a laser saturable absorber with a homogenous widening
}

S. Djabi, H. Boudoukha, M. Djabi, O. Benkherourou

S. Djabi, H. Boudoukha, M. Djabi, O. Benkherourou, "Losses influence of a Fabry Perot resonator on the effect of the optical multistability in a laser saturable absorber with a homogenous widening," Proc. SPIE 9665, Tenth International Topical Meeting on Education and Training in Optics and Photonics, 96651V (3 June 2007); doi: 10.1117/12.2207805

SPIE Event: Tenth International Topical Meeting on Education and Training in Optics and Photonics, 2007, Ottawa, Ontario, Canada 


\title{
Losses Influence of a Fabry Perot resonator on the effect of the optical multistability in a laser saturable absorber with a homogenous widening
}

\author{
S.Djabi, H.Boudoukha, M.Djabi qnd O.Benkherourou \\ Laboratory of the photonic systems and nonlinear optics Department of optics and \\ mechanics of precision, Faculty of Science of the engineer, University of Setif, 19000 \\ Algeria \\ s_djabi@yahoo.fr
}

\begin{abstract}
:
Our work concerns the study of the effect of the optical bistability and multistability in a laser saturable absorber of a Fabry Perot resonator with a homogenous widening. We theoretically studied the influence of the losses of the resonators on the optical bistability by examining mainly the cases where the losses of the resonator depend on the position of the emitted mode of a frequency and the losses of the resonator depend on the density of photons We examined the influence of the physical parameters of laser saturable absorber such as the coefficient of saturation and pumping of the medium active and absorbing on the density of the photons for each loss We showed the effect of the optical bistability and multistability then we analyzed the linear stability of the solutions obtained.
\end{abstract}

Keywords: Optical bistability, Laser saturable absorber, homogenous widening, Losses of a resonator

Tenth International Topical Meeting on Education and Training in Optics and Photonics, edited by Marc Nantel, Proc. of SPIE Vol. 9665, 96651V · (c) 2007 SPIE, OSA, IEEE, ICO doi: $10.1117 / 12.2207805$ 